\title{
PERANCANGAN MODEL TDABC DALAM MENGHITUNG UNIT COST PENDIDIKAN
}

\author{
Tonny Stephanus Eoh \\ Program Studi Akuntansi \\ Fakultas Ekonomi Universitas Kristen Petra \\ Jalan Siwalankerto 121-131, Surabaya
}

\begin{abstract}
Calculation of education unit cost for $S 1$ Economics courses at the University " $X$ " using the TDABC method show that the average tuition fees is $R p$. 3,640,469,/student for the academic year 2015/2016; or Rp. 1,820,235,-/student for each semester. Meanwhile, the basis for calculating the unit cost of education that is used for now, just following the unit cost of its competitors, amounting to Rp. 1.800.000,-/student for each semester. So that the unit cost of education courses calculated by TDABC method and the current method relative did not experience a significant difference. However, the information can be used by management to evaluate the existence of other faculty who use more resources and have fewer number of students.
\end{abstract}

\begin{abstract}
ABSTRAK
Perhitungan unit cost pendidikan untuk program studi S1 Ekonomi di Universitas "X" melalui metode TDABC menyebutkan bahwa rata-rata biaya pendidikan sebesar Rp. 3.640.469,-/mahasiswa untuk tahun ajaran 2015/2016; atau sebesar Rp. 1.820.235,-/mahasiswa per semester. Sementara itu, dasar perhitungan unit cost pendidikan yang digunakan saat ini hanya mengikuti unit cost dari para pesaing yakni sebesar Rp. 1.800.000,-/mahasiswa per semester. Sehingga unit cost pendidikan untuk program studi S1 Ekonomi dengan menggunakan metode TDABC dan yang ada saat ini relatif tidak mengalami perbedaan yang signifikan. Namun, informasi tersebut dapat dijadikan sebagai bahan evaluasi bagi pihak manajemen tentang keberadaan dari fakultas lainnya yang menggunakan lebih banyak resources dan jumlah mahasiswa yang lebih sedikit.
\end{abstract}

Keywords: capacity cost rate, cost drivers rate, cost object, resources, time equations, time-driven activity-based costing (TDABC).

\section{PENDAHULUAN}

Perguruan tinggi sebagai salah satu bentuk organisasi (nirlaba) membutuhkan strategi dalam mencapai tujuannya dan memposisikan organi- sasi tersebut dalam posisi yang unggul dibandingkan dengan organisasi yang sama atau sejenis, guna mencapai keunggulan kompetitif. Pemerintah berencana akan memberi ruang bagi 
universitas asing di Indonesia, sehingga perguruan tinggi dalam negeri harus berinovasi dalam sistem pendidikan dan pengelolaannya. Tujuan dari memberikan izin kepada perguruan tinggi asing agar dunia pendidikan memiliki pembanding dalam hal kualitas.

Standard unit cost pendidikan (objek biaya) untuk perguruan tinggi sangat diperlukan oleh seluruh pihakpihak yang terkait di dalamnya, seperti: pemerintah, masyarakat, dan perguruan tinggi itu sendiri yang berinteraksi secara sinergis, saling terkait dan terpadu. Pengelolaan dan pembiayaan untuk perguruan tinggi swasta dilakukan oleh perguruan tinggi tersebut (Anonymous, 2017). Mengutip pernyataan dari Febri Hendri (Koordinator Divisi Monitoring Pelayanan Publik ICW) bahwa subsidi pemerintah untuk perguruan tinggi negeri (PTN) terus dikurangi sebesar 15 sampai 60 persen yang akan menyebabkan biaya kuliah menjadi semakin mahal, apalagi pemerintah masih membiarkan PTN menentukan sendiri unit cost per mahasiswa. Padahal pungutan tersebut tidak dihitung berdasarkan kebutuhan biaya operasional, melainkan target dana yang harus dicapai dan kemudian membebankannya kepada mahasiswa.

Oleh karena itu, sudah tidak jelas lagi berapa biaya operasional penyelenggaraan pendidikan tinggi serta jangan heran apabila biaya kuliah di PTN sama mahalnya dengan kuliah di perguruan tinggi swasta (PTS) (Anonymous, 2011). Harjono (2008a) menyebutkan bahwa perguruan tinggi diperkirakan akan semakin sulit untuk mengejar standar biaya ideal pelayanan pendidikan kepada mahasiswa. Oleh karena itu perguruan tinggi berencana melakukan penyesuaian biaya kuliah terhadap calon mahasiswa baru.

Universitas "X" merupakan salah satu perguruan tinggi swasta (PTS) yang berlokasi di Surabaya membutuhkan informasi tentang perhitungan unit cost pendidikan yang akurat agar tidak menyebabkan distorsi atas penggunaan dana anggaran, yakni over-absorption maupun underabsorption. Perguruan tinggi layaknya seperti perusahaan jasa lainnya juga membutuhkan informasi dari sistem akuntansi manajemennya dalam perhitungan biaya, dengan tiga tujuan umum yaitu: (Hansen and Mowen, 2006: 4)

1. Menyediakan informasi yang dipergunakan dalam penghitungan harga pokok jasa, produk, dan tujuan lain yang diinginkan manajemen.

2. Menyediakan informasi yang dipergunakan dalam perencanaan, pengendalian, pengevaluasian, dan perbaikan berkelanjutan.

3. Menyediakan informasi untuk pengambilan keputusan.

Berdasarkan dari tiga tujuan umum sistem akuntansi manajemen tersebut, maka pendekatan model dengan menggunakan metode TimeDriven Activity-based Costing (TDABC) merupakan salah satu contoh "tools" bagi pihak perguruan tinggi dalam menghitung unit cost pendidikannya. Menurut Kaplan and Anderson (2007) TDABC memiliki konsep "a simpler and more powerful path to higher profits." TDABC dapat memberikan informasi atas: (1) penentuan proses dan aktivitas utama fakultas; (2) penentuan biaya aktivitas; (3) penelusuran biaya aktivitas pada berbagai objek biaya dari la- 
yanan jasa, mata kuliah, dan mahasiswa; (4) evaluasi terhadap efektivitas dan efisiensi suatu aktivitas, yang dihitung menggunakan satuan waktu dari resources yang diserap. Masalah yang akan dibahas dalam penelitian ini adalah:

1. Bagaimana merancang model perhitungan unit cost pendidikan untuk tahun ajaran 2015/2016 bagi program studi S1 Ekonomi di Universitas "X", melalui metode TDABC berdasarkan aktivitasaktivitas yang teridentifikasi dari penelusuran resources yang digunakan?

2. Bagaimana menghitung capacity cost rate dan unit time dari suatu aktivitas, yang berguna dalam perhitungan unit cost pendidikan melalui time equation?

\section{Penelitian Terdahulu}

Penelitian Tanusaputera (2003) membahas tentang penerapan metode Activity-Based Costing yang bertujuan untuk memberikan informasi biaya yang lebih akurat dalam mengalokasikan biaya unit-unit pendukung di Universitas "X", serta mengetahui surplus dan defisit yang terjadi setelah menggunakan metode tersebut. Kesimpulan dari penelitian tersebut menjelaskan bahwa pengalokasian biaya unit pendukung ke tiap jurusan berdasarkan jumlah mahasiswa dinilai kurang tepat, karena jurusan dengan jumlah mahasiswa yang paling besar akan menanggung biaya yang paling banyak.

Demeere et al. (2009) menjelaskan tentang relevansi dan dampak manajerial TDABC dalam lingkungan outpatient clinic. Sistem TDABC tampaknya sangat cocok karena menggabungkan di samping keuntungan dari sistem $\mathrm{ABC}$ tradisional dengan tambahan fitur adaptasi model yang lebih cepat, setup yang lebih sederhana dan refleksi yang lebih tinggi dan kompleks.

\section{TINJAUAN PUSTAKA}

Horngren et al. (2006: 25) menyatakan "cost as a resource sacrificed or forgone to achieve a specific objective. A cost is usually measured as the monetary amount that must be paid to acquire goods or services." Menurut Hansen dan Mowen (2006: 40-41) biaya adalah kas atau nilai ekuivalen kas yang dikorbankan untuk mendapatkan barang atau jasa yang diharapkan memberi manfaat saat ini atau di masa datang bagi organisasi. Jika biaya telah dihabiskan dalam proses menghasilkan pendapatan, maka biaya tersebut dinyatakan kadaluwarsa (expired) dan biaya yang kadaluwarsa tersebut dikenal dengan beban (expense).

Penentuan biaya yang akurat dilakukan melalui analisis aktivitas. Hansen dan Mowen (2006: 489) berpendapat, analisis aktivitas merupakan proses pengidentifikasian, penjelasan, dan pengevaluasian aktivitas yang dilakukan oleh perusahaan. Empat hasil analisis aktivitas, yaitu: (1) aktivitas-aktivitas apa yang dilakukan; (2) berapa banyak orang yang melakukan aktivitas; (3) waktu dan sumber daya yang dibutuhkan untuk melakukan aktivitas; (4) penghitungan nilai aktivitas untuk organisasi, termasuk rekomendasi untuk memilih dan hanya mempertahankan aktivitas yang memberi nilai tambah (value added).

Objek biaya (cost object) menurut Horngren et al. (2006: 25) "cost object is anything for which a measurement of costs is desired." 
Sedangkan menurut Hilton et al. (2006: 876) "cost object is any end to which a cost is assigned, such as a product unit or a department'. Biaya dapat secara langsung atau tidak langsung berkaitan dengan objek biaya. Biaya langsung (direct cost) adalah biaya yang dengan mudah dan akurat ditelusuri sebagai objek biaya, sedangkan biaya tidak langsung (indirect cost) adalah biaya yang tidak dapat dengan mudah dan akurat dilacak sebagai objek biaya.

Cost pools adalah biaya yang terjadi jika sumber daya digunakan untuk tujuan tertentu dan kadangkadang biaya dikumpulkan ke dalam kelompok tertentu (Blocher et al., 2000:72). Menurut Hilton (2006:141) "cost pools are groups of individual cost items; costs with similar cost drivers or allocation bases are grouped together. Ideally, match the costs with allocations bases or cost drivers that have a cause-and-effect relationship with the cost."

Horngren et al. (2006: 30) menyatakan "a cost driver is a variable, such as the level of activity or volume, that causally effects costs over a given time span. That is, there is a causeand-effect relationship between a change in the level of activity or volume and a change in the level of total costs." Menurut Hansen dan Mowen (2006: 90), penggerak aktivitas merupakan faktor penyebab yang dapat diamati, yang mengukur jumlah sumber daya yang digunakan oleh objek biaya. Penggerak aktivitas menjelaskan perubahan dalam biaya aktivitas dengan mengukur perubahan dalam penggunaan aktivitas atau output. Gambar 1 menunjukkan tentang hubungan antara input, aktivitas, output, dan perilaku biaya.

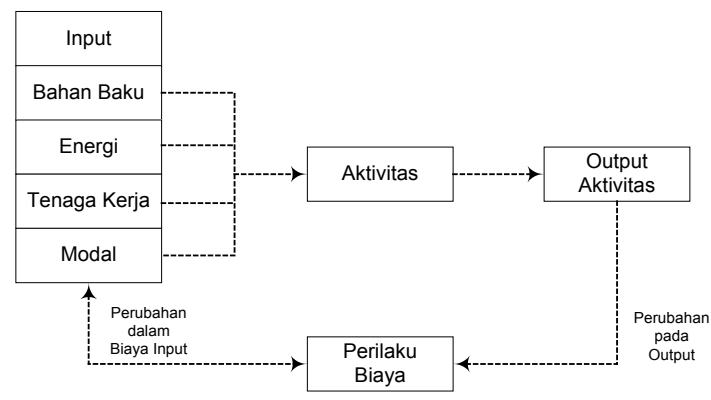

Gambar 1

Model Perilaku Biaya Aktivitas

Sumber: Hansen dan Mowen (2006: 90)

Menurut Hansen dan Mowen (2006: 153) langkah yang harus dilakukan di dalam melakukan perhitungan biaya produk berdasarkan aktivitas yang dikenal dengan ABC (Activity Based Costing) adalah menelusuri biaya aktivitas dan kemudian produk. Tahap awal dalam perancangan sistem perhitungan biaya berdasarkan aktivitas terdiri dari (Hansen dan Mowen, 2006:
154-160): 1. Pengidentifikasian aktivitas dan atributnya; 2. pembebanan biaya ke aktivitas; 3 . pembebanan biaya aktivitas pada aktivitas lain; dan 4 . pembebanan biaya pada produk.

\section{Time-Driven Activity-Based Costing}

TDABC (time-driven activitybased costing) menurut Atkinson et al. (2007: 150) '..., a new approach 
for estimating their cost models. The new approach requires that only two parameters be estimated: (1) the unit cost of supplying capacity for each department or process, (2) The consumption of capacity (unit times) by each transaction or product."

TDABC (Kaplan and Anderson, 2007: 7-8) menyederhanakan proses costing dengan menghilangkan proses interview dan survei para pegawai untuk mengalokasikan resource cost ke aktivitas, sebelum men-drive ke objek biaya. TDABC menentukan resource cost langsung ke objek biaya dengan hanya menggunakan dua set estimasi kerangka yang tidak sulit diperoleh. Pertama, menghitung cost of supplying resource capacity, yaitu menghitung biaya untuk semua sumber daya (seperti: personnel, supervision, occupancy, peralatan, dan teknologi) yang mendukung departemen atau proses ini, yang di sebut dengan total cost by the capacity waktu yang tersedia dari karyawan yang benar-benar melakukan pekerjaan departemennya untuk memperoleh capacity cost rate. Kedua, TDABC menggunakan capacity cost rate untuk menggerakkan departmental resource cost ke objek biaya melalui estimasi kebutuhan kapasitas sumber daya (biasanya waktu) untuk setiap persyaratan objek biaya. Setelah kedua set estimasi ini dilakukan, manajemen dapat langsung menghitung costing untuk setiap proses aktivitas berdasarkan waktu yang dibutuhkan dalam kegiatannya, melalui time equation.

Perhitungan biaya TDABC dilakukan melalui langkah-langkah berikut:

1. Menentukan total biaya yang dibutuhkan untuk menyediakan kapasitas praktis total sebuah departemen atau proses (dalam satuan moneter).

2. Menentukan tarif biaya per kapasitas (capacity cost rate).

Tarif biaya per kapasitas dapat ditentukan dengan cara membagi total biaya yang dibutuhkan untuk menyediakan kapasitas praktis total dengan besaran kapasitas praktis total yang tersedia. Kaplan and Anderson (2007:10) mendefinisikan capacity cost rate, sebagai berikut:

$$
\text { Capacity cost rate }=\frac{\text { Cost of capacity supplied }}{\text { Practical capacity of resources supplied }}
$$

3. Menentukan kapasitas praktis (waktu) yang dibutuhkan untuk melakukan proses-proses yang ada (the demand for resource capacity) Untuk menentukan kapasitas praktis diperlukan persamaan waktu (time equations). Pedoman dasar untuk menciptakan time equations adalah (1) memperkirakan terlebih dahulu waktu minimum dalam melakukan proses; (2) menambahkan faktor-faktor yang menambah waktu proses minimum. Contoh time equation untuk transaksi penjualan (Kaplan dan Anderson, 2007: 31) adalah sebagai berikut:

$$
\begin{aligned}
\text { Inside sales time }= & \text { order entry time }+ \text { new account setup time }+ \text { quoting time } \\
& + \text { order confirmation time }
\end{aligned}
$$




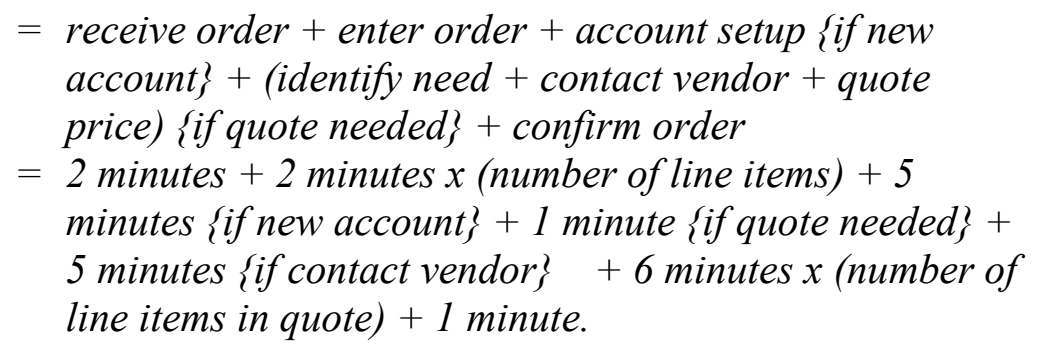

Berdasarkan time equation dari contoh di atas, maka perhitungan matematis secara sederhana dengan metode aljabar, menjadi:

Waktu proses = penjumlahan waktu dari aktivitas individual $=\left(\beta_{0}+\beta_{1} X_{1}\right.$ $+\beta_{2} X_{2}+\beta_{3} X_{3}+\beta_{4} X_{4}+\beta_{5} X_{5}+\ldots \beta_{i}$ $\mathrm{X}_{\mathrm{i}}$ )

di mana:

- $\quad \beta_{0}=$ waktu standar untuk melakukan basic activity. $\beta_{1}=$ perkiraan waktu untuk incremental activity (kegiatan tambahan)

$\mathrm{X}_{1}=$ jumlah incremental activity (seperti; jumlah line items) dst.

4. Mengalokasikan biaya proses pada tiap produk/pelanggan. Setelah mengidentifikasikan tarif biaya per kapasitas dan berapa banyak kapasitas praktis yang diperlukan untuk menyelesaikan suatu proses, maka manajemen dapat langsung mengidentifikasikan berapa banyak biaya yang dibutuhkan untuk menyelesaikan proses-proses yang ada.

\section{Penerapan TDABC di Universitas}

Penerapan TDABC yang berkaitan dengan operasional kegiatan akademik dari suatu universitas, dijelaskan oleh Kaplan and Anderson (2007: 231-243). Pada bagian tersebut dijelaskan tentang salah satu contoh penerapan sistem TDABC di Jackson State University, yang berlokasi di Jackson, Mississippi, dan bagaimana caranya membangun model TDABC berdasarkan pengelompokkan aktivitas-aktivitas kegiatan akademik yang terjadi di universitas, hambatan-hambatan yang terjadi selama pelaksanaan implementasinya, serta tindakan-tindakan yang diusulkan dari project team dalam melakukan pengembangan sistem TDABC. Berikut ini adalah gambar tentang proses membangun model tersebut yang terdiri dari resources, departments, processes dan cost objects.

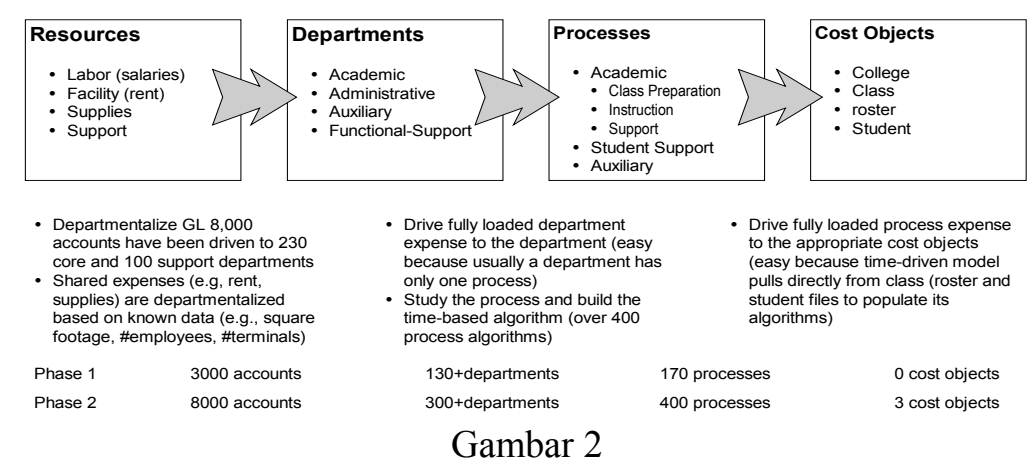

Model-Building Process

Sumber: Kaplan and Anderson (2007: 236) 
Pengembangan dilakukan dengan menetapkan akumulasi biaya yang terdapat di buku besar dengan bagian academic, administrative, dan auxiliary departments yang berhubungan langsung dengan objek biaya, seperti college, class, roster, dan student. Pembentukan objek biaya tersebut menggunakan sumber daya yang berasal dari labor, facility, supplies, dan support yang diproses dan terakumulasikan untuk semua biaya yang digunakan dalam departemen sehingga men-drive biaya menjadi lima proses inti untuk setiap departemen akademik seperti: research grant and development, class preparation, instruction, student sup- port, dan academic improvement. Waktu yang dihabiskan oleh departemen bervariasi untuk setiap prosesnya, sehingga penetapan biaya membutuhkan pendekatan TDABC.

\section{Model Analisis}

TDABC mampu menyederhanakan proses costing dengan hanya membebankan resource cost langsung ke objek biaya berdasarkan aktivitasaktivitas dengan menggunakan time equations. Sepintas, alur TDABC seperti pendekatan traditional costing, namun berbeda pada logika dasar perhitungannya. Bentuk model analisis dari rerangka konseptual TDABC costing seperti terlihat pada Gambar 3.

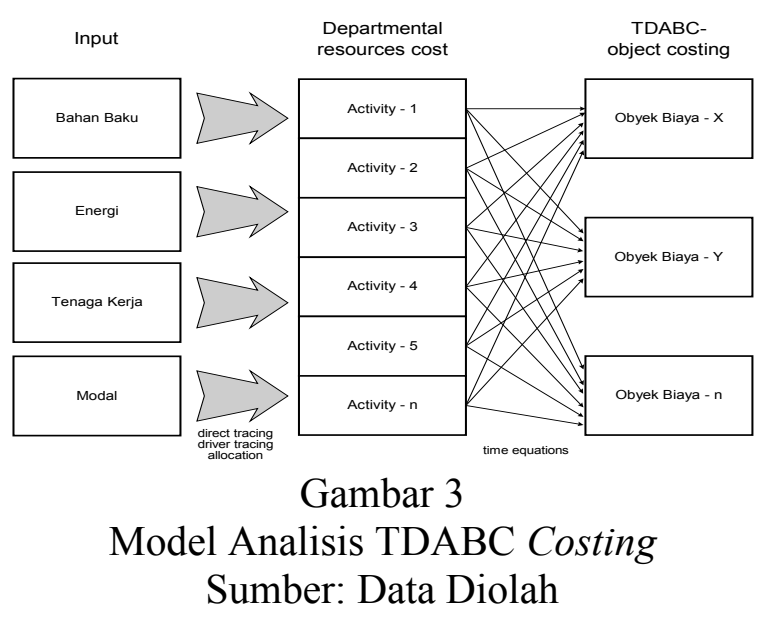

Gambar 3 menunjukkan bahwa input (cost resources) berasal dari sumber daya awal yang akan digunakan dalam perhitungan standard unit cost pendidikan untuk mahasiswa program studi S1 Ekonomi di Universitas "X", yaitu terdiri dari bahan baku, energi, tenaga kerja, dan modal. Sumber daya awal tersebut akan digunakan oleh departemental resources cost yang terdiri dari berbagai macam dan tingkat (level) aktivitas yang terjadi selama proses pengelolaan dana SPP. Selanjutnya, mendeskripsikan tentang aktivitas tersebut melalui pembebanan resource costs ke objek biaya.

Mengestimasikan standar waktu dan mengidentifikasi driver yang dibutuhkan dalam penetapan time equations, dilakukan pada seluruh aktivitas dasar dan seluruh variasi-variasi yang terjadi. Terdapat dua faktor yang dapat menyebabkan cost driver rate berubah, yaitu: (1) perubahan harga sumber daya yang tersedia; (2) pergeseran dalam efisiensi aktivitas. Model time equations dapat disesuaikan seiring perubahan faktor-faktor sistematis yang 
mempengaruhi variasi proses, atau menambah fitur-fitur baru, channels dan jasa. Time equations merupakan estimasi waktu untuk aktivitas yang dibutuhkan dalam bentuk algoritma, guna menghitung objek biaya.
Penjelasan tentang bagaimana resource expenses flow hingga objek biaya dalam aktivitas akademik dapat dilihat pada Gambar 4 berikut ini.

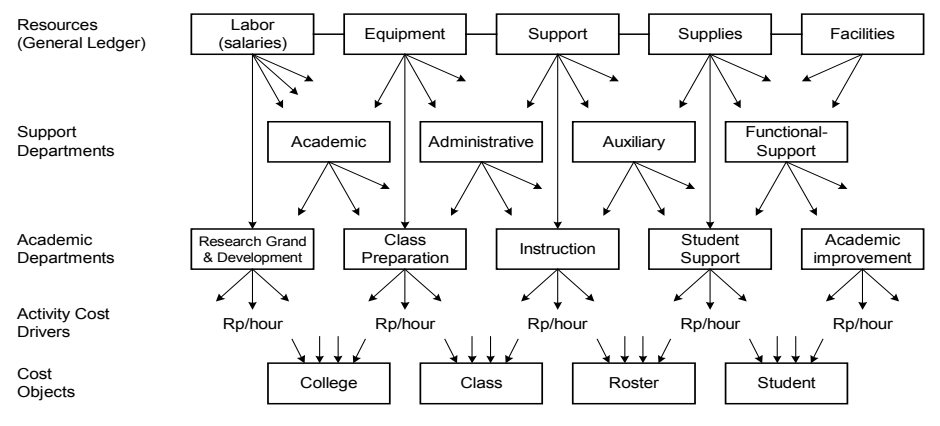

Gambar 4

Resource Expenses Flow to Support and Academic Departments

Sumber: Data Diolah

Gambar 4 menunjukkan hubungan antara sumber daya (resources) sampai dengan objek biaya yang ditimbulkan. Resources yang men-support aktivitas departemen akademik (academic departments) terdiri dari; labor, equipment, support, supplies, dan facilities. Untuk melengkapi pelaksanaan tersebut didukung oleh support department yang terdiri dari: academic, administrative, auxiliary, dan functional-support. Sementara itu, academic departments terdiri dari resources dan support department yang diserap, berupa research grand \& development, class preparation, instruction, student support, dan academic improvement. Selanjutnya, dari academic department tersebut akan membentuk objek biaya (seperti: college, class, roster, dan student) yang dipicu oleh activity cost driver.

\section{METODE PENELITIAN}

Penelitian ini menggunakan metode penelitian kualitatif-eksploratif yang bertujuan untuk menggambarkan secara sistematis tentang fakta dan karakteristik objek yang diteliti secara tepat. Menurut Moleong (2009: 5) penelitian kualitatif adalah penelitian yang menggunakan pendekatan naturalistik untuk mencari dan menemukan pengertian atau pemahaman tentang fenomena dalam suatu latar yang berkonteks khusus. Proses penelitian ini memperlihatkan konteks studi dengan menitikberatkan pada pemahaman, pemikiran, dan persepsi peneliti, di mana hasil dari penelitian ini dapat berupa konsep, teori baru, penemuan baru, pengetahuan aplikatif, serta solusi praktis dari berbagai kajian atau pemikiran ilmiah lainnya untuk memecahkan masalah yang dihadapi.

Rancangan penelitian yang digunakan adalah observasi dan studi kasus. Observasi yang dilakukan dengan melakukan pengamatan langsung atas aktivitas operasional serta melakukan penelitian terhadap permasalahan yang ada dengan melalui studi 
kasus. Menurut Yin (2004: 1) studi kasus merupakan strategi yang lebih cocok bila pokok pertanyaan suatu penelitian berkenaan dengan how atau why. Sehingga diharapkan, melalui penelitian ini dapat membantu pihak universitas dalam memonitor alokasi biaya yang jauh lebih baik bila menggunakan metode Time-Driven Activity Based Costing.

Data yang digunakan untuk penelitian ini tidak menyebutkan secara jelas tentang nama dan alamat dari pihak Universitas "X", karena informasi tersebut disamarkan oleh peneliti, demi menjaga kerahasiaan profil universitas yang bersangkutan. Perhitungan tentang capacity cost rate, cost driver rate, proporsi penyerapan resources dijelaskan hanya satu departemen saja dalam penelitian ini.

Jenis Data yang digunakan dalam penelitian ini:

a. Data Kuantitatif: yaitu data yang dapat dikuantitatifkan, berupa data yang diperoleh dari riset lapangan yang berupa dokumen, angkaangka laporan keuangan (laporan arus kas) di Universitas " $\mathrm{X}$ " tahun ajaran 2015/2016, daftar inventaris dan penyusutannya, nilai gedung dan penyusutannya, daftar ruangan beserta luasnya, daftar mata kuliah yang berlangsung beserta jumlah mahasiswa yang diambil pada tahun ajaran 2015/2016, jumlah mahasiswa aktif, jumlah wisudawan, jumlah dosen tetap dan dosen luar biasa, jumlah pegawai, plotting ruang kuliah/ujian.

b. Data Kualitatif: yaitu data yang tidak dapat dikuantitatifkan, seperti: profil universitas, struktur organisasi, peraturan pemerintah, notulen, job description, standard operational procedure (SOP), dll.
Sumber data yang diperoleh dalam penelitian ini menggunakan data primer: yaitu data yang berasal dari observasi dan wawancara langsung terhadap objek penelitian kepada Biro Administrasi Keuangan (BAK), Biro Administrasi Umum (BAU) dan Biro Administrasi Akademik (BAA). Sumber data primer tersebut berupa: aktivitas-aktivitas yang dilakukan di suatu departemen, metode pencatatan biaya, jumlah mahasiswa yang lulus, jumlah mahasiswa dan lain-lain.

Berdasarkan uraian dari jenis dan sumber data di atas, maka prosedur pengumpulan data yang digunakan adalah melalui teknik: wawancara, observasi, dokumentasi, dan pengkajian referensi untuk diolah sedemikian rupa sehingga dapat digunakan dalam penyusunan penelitian ini.

\section{ANALISIS DAN PEMBAHASAN}

Program pendidikan sarjana (S1) di Universitas "X" dapat ditempuh selama 8 semester dengan jumlah sks sebanyak 144 sks. Adapun fakultas dan program studi yang ada saat ini adalah: 1. Fakultas Hukum (FH); 2. Fakultas Ekonomi (FE): Jurusan Akuntansi dan Jurusan Manajemen; 3. Fakultas Teknik (FT): Jurusan Teknik Arsitektur \& Jurusan Teknik Industri.

Pengelompokan objek biaya yang terjadi di Universitas "X" didasarkan pada dua kategori unit yaitu: unit produksi dan unit pendukung serta administrasi umum, di mana unit produksi secara langsung bertanggung jawab atas pembuatan produk atau jasa pendidikan yang "dijual" ke mahasiswa Universitas " $X$ " (proses belajar mengajar) sedangkan, unit pendukung dan administrasi umum menyediakan pelayanan pendukung yang diperlukan oleh unit produksi. 
Unit produksi adalah inti proses dari kegiatan belajar mengajar (jasa pendidikan) dan merupakan aktivitas pokok (produksi) dalam perhitungan unit cost pendidikan. Unit produksi mengonsumsi sumber daya langsung atas tenaga kerja, material, dan overhead. Input atas sumber daya tenaga kerja langsung yang berhubungan dengan proses belajar mengajar yaitu dosen tetap fakultas dan dosen LB (luar biasa), di mana tugas utamanya adalah memberikan materi perkuliahan dan pengajaran terhadap mahasiswa.

Unit pendukung (supporting unit) yang ada di Universitas "X" terdiri atas pihak-pihak yang men-support kegiatan belajar mengajar dalam fungsi produksi jasa pendidikan. Penggunaan sumber daya overhead dari unit pendukung merupakan sum- ber daya tidak langsung. Adapun overhead tenaga kerja tidak langsung dari unit pendukung terdiri dari: Yayasan, Senat Universitas, Rektor, Wakil Rektor I \& II, Sekretaris Rektorat, Tim Penjamin Mutu, Campus Ministry, Jaringan Kemitraan, LPPM, Pusat Bahasa Asing, Puskom, BAU, BAA, BAK, staf keuangan, dan staf perpustakaan. Sedangkan, unit pendukung untuk administrasi umum terdiri dari staf penerimaan mahasiswa baru, Dekan Fakultas, Ketua Program Studi, staf TU, teknisi, office boy, staf kepegawaian, dan satpam.

Perhitungan kapasitas sumber daya yang digunakan untuk tiap-tiap program studi menggunakan proporsi alokasi tabel jumlah kartu studi tahun ajaran 2015/2016 seperti terlihat pada Tabel 1.

Tabel 1

Jumlah Kartu Studi Tahun Ajaran 2015/2016

\begin{tabular}{|l|r|r|r|r|r|r|r|r|}
\hline \multirow{2}{*}{ Semester } & Hukum & \multicolumn{3}{|c|}{ Ekonomi } & \multicolumn{3}{|c|}{ Teknik } & \multirow{2}{*}{ Total } \\
\cline { 2 - 9 } & IH & EM & EA & Total & TI & TA & Total & \\
\hline \hline Semester-Gasal & 48 & 137 & 176 & $\mathbf{3 1 3}$ & 39 & 37 & 76 & 437 \\
\hline Semester-Genap & 42 & 110 & 135 & $\mathbf{2 4 5}$ & 29 & 27 & 56 & 343 \\
\hline \hline Total & 90 & & & $\mathbf{5 5 8}$ & & 132 & 780 \\
\hline Persentase & $12 \%$ & & & $\mathbf{7 2 \%}$ & & $17 \%$ & $100 \%$ \\
\hline Proporsi & 1,00 & & & $\mathbf{6 , 2 0}$ & & & 1,47 & 8,67 \\
\hline
\end{tabular}

Sumber: Data Diolah

Langkah pertama yang harus dilakukan dalam perancangan model TDABC untuk penentuan standard unit cost pendidikan untuk program studi S1 Ekonomi di Universitas "X" adalah: (1) menentukan kamus aktivitas dari unit pendukung dalam melakukan kegiatan operasionalnya; (2) menentukan penggerak aktivitas (cost driver) dari tiap-tiap aktivitas; (3) menentukan berapa lama waktu yang dibutuhkan dari tiap-tiap aktivitas tersebut berdasarkan estimasi unit time rata-rata yang dibutuhkan; dan (4) menentukan banyaknya jumlah peker- jaan (quantities of work) dari tiap-tiap aktivitas. Adapun rincian informasi tentang unit cost pendidikan berasal dari laporan arus kas Universitas " $X$ " untuk tahun ajaran 2015/2016 (bulan September 2015 s/d Agustus 2016).

Langkah kedua yaitu menjelaskan persamaan waktu yang dibutuhkan di setiap aktivitas (unit time) pada masing-masing departemen (BAU, BAK, FE) dengan banyaknya jumlah pekerjaan (quantities of work) dari tiap-tiap aktivitas tersebut ke dalam time equations. Berikut adalah salah satu contoh penjelasan dari time 
equations untuk departemen BAK saja:

Departemen BAK time (menit)= $45 \times$ jumlah mahasiswa baru $(\mathrm{FE})+$ $35 \mathrm{x}$ jumlah mahasiswa aktif dari $\mathrm{FE}+$ $35 \mathrm{x}$ jumlah mahasiswa penunggak denda dari $\mathrm{FE}+40 \mathrm{x}$ jumlah penerima gaji +35 x jumlah peserta ujian skripsi $+35 \mathrm{x}$ jumlah pembuat legalisir +35 jumlah peserta wisuda dari $\mathrm{FE}$

Langkah ketiga menghitung $c a-$ pacity cost rate bagi unit-unit pendukung per departemen (BAU, BAK, FE) untuk periode 1 tahun. Berikut contoh perhitungan untuk departemen BAK. BAK:

Untuk tenaga kerja departemen
Capacity Cost Rate - tenaga kerja = Rp. 31.824.000,- : $193.882=$ Rp. 164,14/menit.

Untuk ruang dan area departemen BAK:

Capacity Cost Rate - ruang dan area $=$ Rp. 768.000,- : $193.882=\mathrm{Rp}$. 3,96/menit.

Untuk inventaris departemen BAK:

Capacity Cost Rate - inventaris $=\mathrm{Rp}$. 4.674.338,- : $193.882=\mathrm{Rp}$. 24,11/menit.

Langkah keempat menghitung TDABC cost driver rate untuk setiap aktivitas yang diestimasikan dalam satuan waktu (unit time) sesuai kamus aktivitas. Tabel 2 akan memberikan penjelasan hanya untuk departemen BAK saja.

Tabel 2

TDABC Cost Driver Rate - Departemen BAK

\begin{tabular}{|c|l|r|r|r|r|}
\hline \multirow{2}{*}{ No. } & \multirow{2}{*}{ Activity } & \multicolumn{4}{|c|}{ TDABC Cost Driver } \\
\cline { 3 - 6 } & & $\begin{array}{c}\text { Unit Time } \\
\text { (menit) } \\
(3)\end{array}$ & $\begin{array}{c}\text { Rate-tenaga kerja } \\
\text { (at Rp 164,14/menit) } \\
(4)\end{array}$ & $\begin{array}{c}\text { Rate-ruang \&area } \\
\text { (at Rp 3,96/menit) }\end{array}$ & $\begin{array}{c}\text { Rate-inventaris } \\
\text { (at Rp 24,11/menit) }\end{array}$ \\
\hline 1 & Menerima uang masuk & 45 & $7,386.36$ & 178.25 & $1,084.92$ \\
\hline 2 & Menerima SPP & 35 & $5,744.95$ & 138.64 & 843.82 \\
\hline 3 & Menerima denda & 35 & $5,744.95$ & 138.64 & 843.82 \\
\hline 4 & Membayar gaji & 40 & $6,565.66$ & 158.45 & 964.37 \\
\hline 5 & Menerima uang skripsi & 35 & $5,744.95$ & 138.64 & 843.82 \\
\hline 6 & Menerima uang legalisir & 35 & $5,744.95$ & 138.64 & 843.82 \\
\hline 7 & Menerima uang wisuda & 35 & $5,744.95$ & 138.64 & 843.82 \\
\hline
\end{tabular}

Sumber: Data Diolah

Langkah kelima adalah menghitung besarnya penyerapan resources dari setiap aktivitas dan tingkat efisiensi dari kapasitas yang dimiliki oleh masing-masing departemen dengan menghitung cost of performing activities. Kajian teori menyebutkan bahwa TDABC cost driver rate sedikit lebih rendah dari estimasi model $\mathrm{ABC}$ konvensional, karena tidak semua/ seluruh resources yang ada akan habis terpakai melainkan masih ada kapasitas yang tidak digunakan/dipakai (unused capacity). Sementara itu, quantity merupakan banyaknya jumlah pekerjaan (quantities of work). Perhitungan cost of performing activities untuk departemen BAK saja seperti terlihat pada Tabel 3. 
Tabel 3

Cost of Performing Activities - Departemen BAK

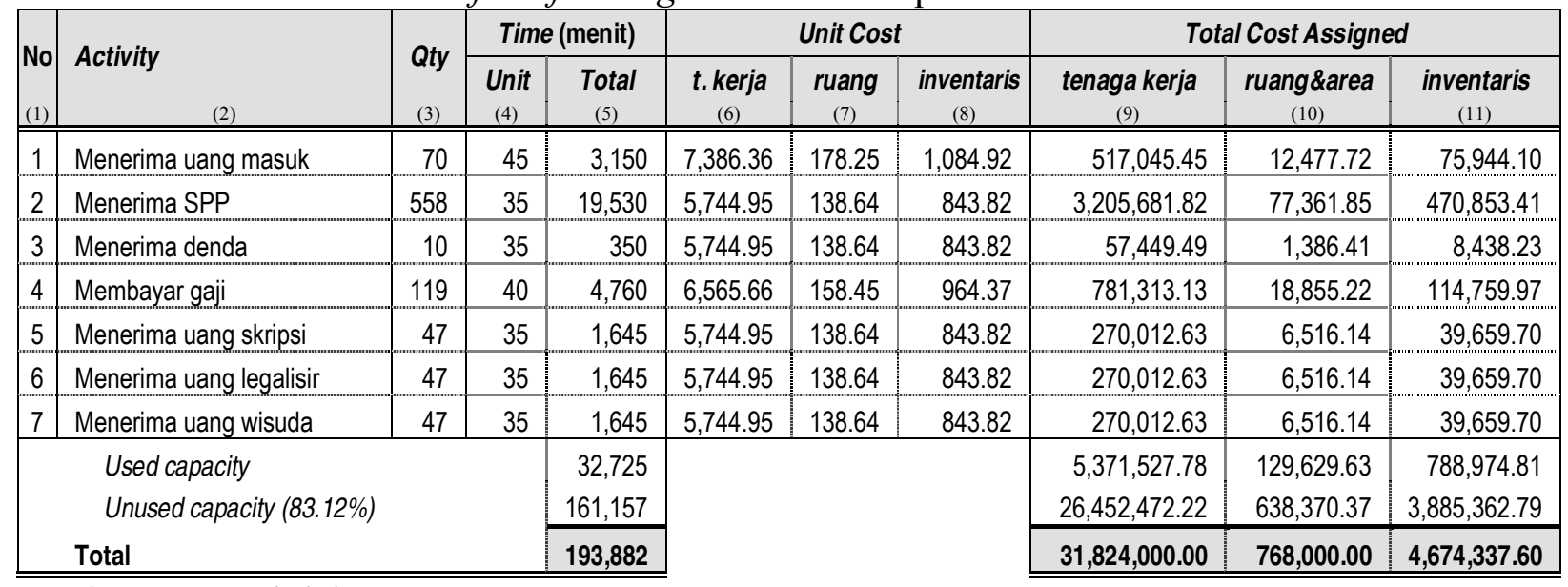

Sumber: Data Diolah

Langkah terakhir untuk perhitungan unit cost pendidikan yaitu menghitung besarnya penggunaan dan penyerapan atas sumber daya (resources) yang digunakan oleh unit produksi maupun unit pendukung dan administrasi umum, yang terdiri dari tenaga kerja, material dan overhead.

Input sumber daya (dosen tetap) yang terkait secara langsung atas tenaga kerja dalam kegiatan proses belajar mengajar sebesar Rp 122.276.667,- untuk tahun ajaran 2015/2016. Sementara itu, perhitungan biaya tenaga kerja langsung atas dosen LB sebesar Rp 48.664.000,- untuk tahun ajaran 2015/2016.

Biaya untuk tenaga pengawas (UTS dan UAS) adalah sebesar Rp 2.620.000,-. Evaluasi akhir atas materi perkuliahan dari proses belajar mengajar berupa ujian (UTS dan UAS) sebesar Rp 10.480.000,-. Biaya honorarium yang diterima oleh dosen pembimbing sebesar Rp 100.000,untuk satu mahasiswa. Berdasarkan daftar wisudawan mahasiswa S1 sebanyak 47 alumni, maka dapat dihitung biaya honorarium untuk dosen pembimbing yakni sebesar $\mathrm{Rp}$
4.700.000,- Setiap penyusunan tugas akhir akan diuji untuk memperoleh nilai akhir atas kelayakan di dalam penyusunan skripsi. Adapun honorarium yang diterima oleh dosen penguji adalah Rp 50.000,- untuk setiap mahasiswa yang ujian, sedangkan pelaksanaan ujian skripsi tersebut membutuhkan 3 orang tenaga penguji sehingga total biaya untuk tenaga penguji sebesar Rp 7.050.000,- (47 x 3 dosen penguji x Rp 50.000).

Nilai penyusutan gedung Universitas "X" telah direvaluasi dan masih memiliki nilai manfaat sebesar $60 \%$ dari total NJOP, serta ditaksir masih memiliki umur manfaat selama 20 tahun dengan nilai yakni sebesar Rp. 3.340.800.000,-. Berdasarkan dari data tersebut, maka dapat dihitung total nilai penyusutan gedung untuk setiap tahunnya yaitu:

$$
\frac{\text { Rp. } 3.340 .800 .000}{20 \text { tahun }}=\operatorname{Rp~167.040.000,-~}
$$

Nilai penyusutan gedung dalam satuan meter persegi $\left(\mathrm{m}^{2}\right)$ untuk setiap tahunnya:

$$
\frac{\text { Rp. } 167.040 .000}{2784 \mathrm{~m}^{2}}=\mathrm{Rp} 60.000,-/ \mathrm{m}^{2}
$$


Alokasi biaya atas penggunaan ruangan yang dialokasikan untuk aktivitas Fakultas Ekonomi sebesar Rp. 17.520.000,-. Overhead atas inventaris yang digunakan oleh Fakultas Ekonomi dan masih memiliki nilai ekonomis untuk kegiatan unit produksi sebesar Rp. 6.841.677,- (Rp 3.940.222 untuk kelompok penyusutan 4 tahun dan Rp. 2.901.456 untuk kelompok 8 tahun). Input resources atas tenaga kerja yang men-support unit produksi berasal dari tenaga kerja tidak langsung bagi unit pendukung sebesar Rp. 289.795.240,- setelah dialokasikan ke Fakultas Ekonomi. Tenaga kerja tidak langsung untuk administrasi umum dari unit pendukung sebesar Rp. 124.598.667,--.

Diketahui sebelumnya nilai penyusutan gedung untuk setiap tahunnya yakni sebesar Rp. 60.000,- yang dihitung dalam satuan meter persegi $\left(\mathrm{m}^{2}\right)$. Adapun nilai gedung dalam satuan $\mathrm{m}^{2}$ tersebut dikalikan dengan luas ruangan/area dari masing-masing unit pendukung, selanjutnya diproporsikan ke Fakultas Ekonomi (alokasi) sebesar asumsi resources yang digunakan. Total biaya overhead sebesar Rp. 43.920.000,- (setelah dialokasikan).

Overhead atas inventaris yang digunakan oleh unit pendukung dalam men-supply unit produksi dan masih memiliki nilai ekonomis periode bulan September 2015 s/d Agustus 2016 adalah sebesar Rp. 54.244.559,- (Rp 35.825.753,- untuk kelompok penyusutan 4 tahun dan Rp. 18.418.806,untuk kelompok 8 tahun). Sementara itu, biaya penyusutan inventaris peralatan dan perlengkapan bagi unit pendukung - administrasi umum yang telah dialokasikan adalah sebesar Rp. 8.898.827,- (Rp. 2.412.180,- untuk ke- lompok penyusutan 4 tahun dan Rp. 6.486.648,- untuk kelompok 8 tahun).

Selain inventaris peralatan dan perlengkapan, terdapat pula inventaris perangkat lunak (software) yang digunakan oleh unit pendukung dan masih memiliki nilai ekonomis sebesar Rp. 38.713.463,-. Inventaris lainnya yang masih memiliki nilai ekonomis dan digunakan oleh unit pendukung adalah kendaraan, dengan total biaya penyusutan inventaris kendaraan sebesar Rp. 3.884.170,-.

Kelompok biaya rutin merupakan biaya-biaya yang secara regular terjadi dalam menunjang kegiatan operasionalnya, di mana rincian informasi biaya rutin yang dibayar setiap bulannya oleh Universitas "X" untuk tahun ajaran 2015/2016 sebesar Rp. 112.973.453,-.

Kelompok biaya kegiatan merupakan biaya-biaya yang tidak secara rutin terjadi melainkan akibat dari suatu agenda kegiatan tertentu di salah satu unit yang ada sebesar Rp. 100.461.197,- pada tahun ajaran 2015/ 2016. Kelompok biaya pemeliharaan dan maintenance merupakan biayabiaya yang timbul karena kebutuhan dari unit pendukung untuk menjaga dan memperbaiki fasilitas dan sarana yang dimiliki sebesar Rp.15.194.040,-.

Berdasarkan perhitungan penggunaan dan penyerapan resources, maka selanjutnya menyusun total biaya pendidikan untuk program studi S1 Ekonomi untuk tahun ajaran 2015/ 2016. Setiap resources yang digunakan oleh unit produksi maupun unit pendukung dan administrasi umum dihitung sesuai proporsi yang dibebankan di Universitas "X". Berikut ini adalah perhitungan total biaya pendidikan. 


\section{Perhitungan Total Biaya Pendidikan untuk Program Studi S1 Ekonomi Tahun Ajaran 2015/2016}

\begin{tabular}{lr} 
Tenaga kerja langsung: & \\
Dosen tetap & \\
Dosen LB \& dosen tetap non-FE & \\
Tenaga Vokasi: & $2,620,000$ \\
$\quad$ Pengawas ujian & $2,620,000$ \\
$\quad$ Pembuat soal ujian & $10,480,000$ \\
$\quad$ Pemeriksa lembar jawaban & $4,700,000$ \\
$\quad$ Pembimbing tugas akhir & $7,050,000$ \\
$\quad$ Penguji tugas akhir & \\
& \\
& \\
& \\
Overhead: & \\
Ruang kuliah-unit produksi & $17,520,000$ \\
Inventaris-unit produksi & $6,841,677$ \\
TKTL-unit pendukung & $289,795,240$ \\
TKTL-administrasi umum & $124,833,667$ \\
Ruangan \& area-unit pendukung & $43,920,000$ \\
Inventaris kantor-unit pendukung & $54,244,559$ \\
Inventaris kantor-admin. Umum & $8,898,827$ \\
Inventaris perangkat lunak & $38,713,463$ \\
Inventaris kendaraan & $3,884,170$ \\
Belanja barang \& maintenance: & \\
Total biaya rutin & $112,973,453$ \\
Total biaya kegiatan & $100,461,197$ \\
Total biaya pemeliharaan \& maintenance & $15,194,040$ \\
\cline { 2 - 2 } &
\end{tabular}

Total biaya overhead

$122,276,667$

$48,664,000$

Total biaya

$817,280,292$

$1,015,690,958$
Setelah menghitung total biaya, maka tahap selanjutnya adalah menghitung jumlah mahasiswa Fakultas Ekonomi untuk tahun ajaran 2015/ 2016 berdasarkan dari Tabel 1. Berdasarkan Tabel 1 tersebut diketahui bahwa total mahasiswa yang mengikuti perkuliahan untuk semester gasal dan genap tahun ajaran 2015/2016 sebanyak 558 mahasiswa (313 mahasiswa semester gasal dan 245 mahasiswa semester genap), maka perhitungan rata-rata adalah:

Rata-rata mahasiswa Fakultas Ekonomi tahun ajaran 2015/2016 $=(313+$ 245) $/ 2=279$ mahasiswa

Proses pembagian antara perhitungan total biaya pendidikan untuk program studi S1 Ekonomi dengan jumlah mahasiswa Fakultas Ekonomi untuk tahun ajaran 2015/2016 merupakan rata-rata unit cost pendidikan bagi program studi S1 Ekonomi untuk tahun ajaran 2015/2016. Besarnya rata-rata unit cost tersebut adalah:

Rp. 1.015.690.958,- : 279 mahasiswa $=$ Rp. 3.640.469,-/mahasiswa/tahun. Jadi nilai rata-rata unit cost pendidikan per semester untuk tahun ajaran 2015/ 2016 bagi program studi S1 Ekonomi, sebesar Rp 1.820.235,- per mahasiswa per semester (Rp. 3.640.469,- dibagi 2 semester gasal dan genap).

Dasar perhitungan unit cost pendidikan yang ada saat ini (sesuai tarif harga dari pesaing) dengan TDABC mendekati angka yang relatif sama yakni Rp. 1.800.000,- berbanding dengan Rp. 1.820.235,-. Hal ini menjelaskan bahwa biaya pendidikan 
untuk tahun ajaran 2015/2016 dari fakultas ekonomi dengan jumlah mahasiswa sebanyak 279 mahasiswa 'relatif' mengalami break even point (BEP); atau tidak terjadi surplus maupun defisit.

Pertanyaan lanjutan yang muncul dan dapat dijadikan sebagai bahan evaluasi bagi pihak manajemen Universitas "X" adalah apabila dikaitkan dengan fakultas selain Fakultas Ekonomi (yaitu: Fakultas Teknik dan Fakultas Hukum) di mana jumlah mahasiswanya lebih sedikit serta menggunakan resources ruang dan area yang lebih luas, maka dapat disimpulkan bahwa fakultas lain akan mengalami defisit keuangan, yakni pengeluaran biaya pendidikan tidak sebanding dengan penerimaan yang diperoleh untuk tahun ajaran 2015/2016. Hal tersebut secara tidak langsung akan berdampak pada kinerja Fakultas Ekonomi apabila dilihat secara global (menggabungkan seluruh fakultas), yakni seakan-akan mengalami defisit keuangan juga.

\section{SIMPULAN}

Simpulan yang dapat diberikan berdasarkan analisis yang telah dilakukan adalah tahun ajaran 2015/2016 menunjukkan 'relatif' tidak mengalami defisit ataupun surplus keuangan, tetapi mempunyai kecenderungan break even point (BEP). Asumsi tersebut diperoleh dari tidak adanya perbedaan angka yang mencolok antara unit cost yang digunakan saat ini (hanya mengikuti unit cost dari universitas pesaing) dengan menggunakan perhitungan TDABC, yakni Rp. 1.800.000,- berbanding dengan Rp. 1.820.235,-- Namun, patut diperhatikan oleh pihak manajemen bahwa jumlah rata-rata mahasiswa aktif dari Fakultas Ekono- mi untuk periode tersebut sebanyak 279 mahasiswa (lebih banyak dari fakultas lainnya), maka secara keseluruhan pihak Fakultas Ekonomi akan terbebani oleh fakultas lainnya yang mengalami defisit keuangan.

Evaluasi kinerja untuk setiap aktivitas yang dilakukan oleh departemen/bagian harus dilakukan secara berkala, di mana perbaikan yang berkesinambungan tersebut akan membuat unit time menjadi lebih efisien. Pelatihan dan diklat merupakan cara untuk meningkatkan kualitas tenaga kerja sehingga unused capacity dapat ditekan semaksimal mungkin.

\section{SARAN}

Penggunaan unit time yang lebih efisien atas aktivitas akan mengurangi unused capacity, melalui pelatihan secara berkala sehingga menyebabkan karyawan menjadi lebih terampil. Alternatif lain adalah melakukan restrukturisasi ulang dengan mengalihkan kelebihan kapasitas tersebut kepada departemen lainnya yang lebih membutuhkan.

Pengendalian atas aktivitas-aktivitas yang menggunakan resources sangat diperlukan agar terjadi efisiensi biaya. Oleh karena itu, aktivitas-aktivitas yang tidak bernilai tambah (nonvalue-added) harus dieliminasi atau dikurangi agar tidak terjadi pemborosan terhadap resources.

\section{DAFTAR KEPUSTAKAAN}

Anonymous, 2011, Duh, Biaya Kuliah Di PTN Kian Mahal, Harian Rakyat Merdeka, Diakses pada 19 Mei 2017 pukul 22:30 dari http://ekbis. rmol.co/read/2011/12/06/47975/ Duh,-Biaya-Kuliah-Di-PTN-KianMahal-. 
2017, Catat! Kampus Swasta Harus Percaya Diri Bersaing dengan Perguruan Tinggi Negeri, Okezone News, Diakses pada 12 Desember 2017 pukul 22:30 dari https://news.Okezone.com/read/201 7/11/11/65/1812397/catat-kampusswasta-harus-percaya-diri-bersaingdengan-perguruan-tinggi-negeri.

Antonius, 2003, Penerapan Departmental Costing dalam Alokasi Biaya Unit-unit Pendukung ke Unitunit Akademik di Universitas ' $X$ ', Skripsi, Program Studi Akuntansi, Universitas Kristen Petra, Surabaya.

Atkinson, Anthony A., Robert S. Kaplan, Ella Mae Matsumura and S. Mark Young, 2007, Management Accounting, Fifth Edition, Pearson Prentice Hall, Upper Saddle River, New Jersey.

Blocher, Edward J., Kung H. Chen, dan Thomas W. Lin, 2000, Manajemen Biaya: Dengan Tekanan Stratejik, Buku 1, Penerbit Salemba Empat, Jakarta.

Demeere, Nathalie, Kristof Stouthuysen, and Filip Roodhooft, 2009, Time-Driven Activity-Based Costing in An Outpatient Clinic Environment: Development, Relevance and Managerial Impact, Journal of Elsevier, G Model HEAP-2348, Health Policy, xxx-xxx.

Hansen, Don R. and Maryanne M. Mowen, 2003, Management Accounting, $6^{\text {th }}$ edition, South-Western Publishing Co., Mason, Ohio.

--, 2006, Management Accounting (Akuntansi Manajemen), Edisi 7 (terjemahan), Buku 1, Penerbit Salemba Empat, Jakarta.
Harjono, Yulvianus, 2008a, Perguruan Tinggi Siap-siap Naikkan Biaya, Kompas.com, Diakses pada 12 Desember 2017 pukul 23:05 dari http://nasional.kompas.com/read/20 08/05/25/20003294/www.kompas.c om.

--, 2008b, Minat Mahasiswa Masuk PTS Turun, Kompas.com, Diakses pada 13 Desember 2017 pukul 13:10 dari http://nasional. kompas.com/read/2008/08/11/1800 4863/minat.mahasiswa.masuk.pts.tu run.

Hilton, Ronald W., 2002, Managerial Accounting: Creating Value in a Dynamic Business Environment, Fifth Edition, McGraw-Hill Companies, Inc., New York.

Hilton, Ronald W., Michael W. Maher and Frank H. Selto, 2006, Cost Management: Strategies for Business Decisions, Third Edition, McGraw-Hill Companies, Inc., New York.

Horngren, Charles T., Srikant M. Datar and George Foster, 2006, Cost Accounting: A managerial Emphasis, Twelfth Edition, Pearson Prentice Hall, Upper Saddle River, New Jersey.

Kaplan, Robert S. and Steven R. Anderson, 2007, Time-Driven Activity-Based Costing: A Simpler and More Powerful Path to Higher Profits, Harvard Business School Publishing, Massachusetts.

Moleong, Lexy, 2009, Metodologi Penelitian Kualitatif, Cetakan-26, PT Remaja Rosda Karya, Bandung. 
Mulyadi, 2007, Activity-Based Cost System, Edisi ke-6, Cetakan ke-2, UPP STIM YKPN, Yogyakarta.

Pernot, Eli, Filip Roodhooft, and Alexandra Van den Abbeele, 2007, Time-Driven Activity-Based Costing for Inter-Library Services: A Case Study in a University, Journal of Academic Librarianship, Vol. 33, No. 5, page 551-560.

Soeherman, Bonnie. 2007, Time-Driven Activity-Based Costing: Penyederhanaan Kompleksitas Strategic Cost Management dalam Pencapaian Strategi, Jurnal Akuntansi dan Teknologi Informasi, Vol. 6, No. 2, page 108-120.

Stouthuysen, Kristof, Michael Swiggers, Anne-Mie Reheul and Filip Roodhooft, 2010, TimeDriven Activity-Based Costing for a Library Acquisition Process: A Case Study in a Belgian University, Journal of Elsevier Library Collections, Acquisitions, \& Technical Services, page 83-91.

Susanti, Reh Atemalem, 2007, PTS Minta Pajak Dihapus, Tempo Interaktif, Diakses pada 13 Desember 2017 pukul 20:45 dari http://www.tempo.co/read/news/20 07/02/19/05593692/PTS-MintaPajak-Dihapus.

------, 2007, Pemerintah Tak Anggarkan Dana Untuk Perguruan Tinggi Swasta, Tempo Interaktif, Diakses pada 11 Desember 2017 pukul 23:00 dari http://www. tempo.co/read/news/2007/02/22/05 593922/Pemerintah-Tak-Anggarkan-Dana-Untuk-Per-guruan-Tinggi-Swasta.
Szychta, Anna, 2010, Time-Driven Activity-Based Costing in Service Industries, Journal of Social Sciences/Socialiniai Mokslai, page 49-60.

Tanusaputera, Megawati, 2003, Penerapan Activity-Based Costing dalam Alokasi Biaya Unit-unit Pendukung ke Unit-unit Akademik di Universitas ' $X$ ', Skripsi, Program Studi Akuntansi, Universitas Kristen Petra, Surabaya.

Tse, Michael S.C. and Maleen Z. Gong, 2009, Recognition of Idle Resources in Time-Driven ActivityBased Costing and Resource Consumption Accounting Model, Journal of JAMAR, Vol. 7, No. 2, page 41-54.

Yin, Robert K., 2004, Studi Kasus: Desain dan Metode, Edisi Ketiga, PT. Raja Grafindo Persada, Jakarta. 